\title{
Foraging strategies of the black-legged kittiwake Rissa tridactyla at a North Sea colony: evidence for a maximum foraging range
}

\author{
F. Daunt ${ }^{1}$, S. Benvenuti ${ }^{2}$, M. P. Harris ${ }^{1}$, L. Dall'Antonia ${ }^{3}$, D. A. Elston ${ }^{4}$, S. Wanless ${ }^{1, *}$ \\ ${ }^{1}$ NERC Centre for Hydrology and Ecology, Banchory Research Station, Hill of Brathens, Banchory AB31 4BW, \\ United Kingdom \\ ${ }^{2}$ Dipartimento di Etologia, Ecologia ed Evoluzione, Università di Pisa, Via Volta 6, 56126 Pisa, Italy \\ ${ }^{3}$ Consiglia Nazional delle Ricerche, Istituto di Elaborazione dell'Informazione, Via Santa Maria 46, 56100 Pisa, Italy \\ ${ }^{4}$ BioSS, Environmental Modelling Unit, Macaulay Land Use Research Institute, Craigiebuckler, Aberdeen AB15 8QH, \\ United Kingdom
}

\begin{abstract}
Black-legged kittiwakes Rissa tridactyla on the Isle of May, southeast Scotland, feed predominantly on the lesser sandeel Ammodytes marinus, an abundant, pelagic fish that is currently the subject of the largest fishery in the North Sea. The population of black-legged kittiwakes on the Isle of May is declining, and the fishery has been implicated. In order to assess this concern, there is an urgent need to improve our understanding of the factors that affect black-legged kittiwake foraging behaviour. During 1999, we carried out a detailed study of the foraging strategies of black-legged kittiwakes using purpose-built activity loggers that allowed us to distinguish 4 key behaviours: travelling flight, foraging flight, presence on the sea surface and attendance at the nest. We used the data to model 2 key aspects of time allocation at sea: (1) the relationship between the travelling time and trip duration and (2) the ratio of time spent actively foraging to time of inactivity on the sea surface at the foraging grounds. We found that a broken-stick model with a flat asymptote was the best fit for the relationship between travelling time and trip duration. Using published flight speeds for this species, we calculate that breeding black-legged kittiwakes on the Isle of May had a maximum range of $73 \pm 9 \mathrm{~km}$ from the colony. We speculate that this upper limit is dictated by the distribution of prey rather than any energetic constraint on flight costs: a large sand bank complex, known to have high concentrations of lesser sandeels, lies entirely within this range. There was no consistent pattern in the ratio of the active to inactive components of the foraging trip, suggesting that this species exhibits highly flexible foraging strategies at sea, probably reflecting the patchy and unpredictable distribution and availability of its prey. Our findings suggest that the birds are feeding on sandeels at the same time and in the same area as the operations of the sandeel fishery.
\end{abstract}

KEY WORDS: Industrial fisheries $\cdot$ Lesser sandeel $\cdot$ Ammodytes marinus $\cdot$ Seabirds $\cdot$ Time allocation · Predator-prey

Resale or republication not permitted without written consent of the publisher

\section{INTRODUCTION}

To implement successful conservation strategies for declining or threatened species, a good understanding of their foraging ecology is essential. Obtaining this

${ }^{*}$ Corresponding author. Email: swanl@ceh.ac.uk knowledge is particularly difficult in the context of the marine environment, because of the huge logistical and financial constraints involved. In the case of marine top predators, the advent of miniaturised activity loggers (e.g. Dall'Antonia et al. 1993) has provided us with a useful tool to measure time allocation at sea. Among seabirds, these instruments enable us to distin- 
guish the key behaviours common to most volant species, notably travelling flight, active foraging, and presence on the sea surface. How individuals allocate time to each activity is a very useful measure of the energetic constraints under which the bird is operating, which is a product of the state of the individual and its dependants and the state of the environment where it must find food.

One seabird species of recent conservation concern is the black-legged kittiwake Rissa tridactyla, a widely distributed colonial seabird breeding in arctic and temperate regions of the North Pacific and North Atlantic (Harrison 1983). There is a large United Kingdom population concentrated along the northwestern edge of the North Sea (Lloyd et al. 1991). Since the late 1980s, black-legged kittiwakes have been the subject of a United Kingdom-wide programme to monitor annual breeding success and population size. This research has highlighted a dramatic decline in productivity and population size that is particularly severe in colonies in southeast Scotland and northeast England (Wanless \& Harris 1992, Harris \& Wanless 1997, Hemsley 1999, Upton et al. 2000). Breeding black-legged kittiwakes from these colonies feed predominantly on the lesser sandeel Ammodytes marinus, and recent evidence points to low availability of this prey species as the main cause of poor productivity (Rindorf et al. 2000, Lewis et al. 2001b). Black-legged kittiwakes are predicted to be particularly vulnerable to variations in food availability primarily because they are surface feeders and have a very limited capacity to switch prey (Furness \& Tasker 2000). They have been used widely as an indicator of marine conditions in the North Atlantic and North Pacific (Aebischer et al. 1990, Gill et al. 2002).

The lesser sandeel is subject to the largest fishery in the North Sea (Gislason \& Kirkegaard 1998; ICES 2001) and there is considerable concern that the fishery may be partly responsible for the black-legged kittiwake's recent decline. At-sea distributions of blacklegged kittiwakes have demonstrated considerable overlap in the areas used, and the timing of the fishery coincides with the birds' breeding season (Wanless et al. 1998, Rindorf et al. 2000). Breeding adults are potentially more vulnerable to local fluctuations in prey availability for 2 main reasons. First, the energetic requirements of rearing offspring successfully are high (Golet et al. 2000, Gill \& Hatch 2002, Suryan et al. 2002). Second, breeding adults are limited in the area they can exploit by the need to return to the colony to feed the young (Orians \& Pearson 1979). Thus, there is a clear need for information about the foraging activity and behaviour of black-legged kittiwakes at this time.

To date, most information on at-sea distribution and foraging behaviour have been obtained from direct observations. A disadvantage of such studies is that the origin and status of the individuals is unknown. To obtain data on birds of known breeding status, it is necessary to carry out colony-based work. We measured foraging activity of breeding black-legged kittiwakes using miniaturised activity loggers (Dall'Antonia et al. 1993), which have been used successfully to record the homing behaviour and foraging strategies in a number of species (e.g. Papi et al. 1991, Dall'Antonia et al. 1995, 2001, Benvenuti et al. 1998, 2001, 2002, Bonadona et al. 2000, Garthe et al. 2000, Falk et al. 2000, 2002, Lewis et al. 2002). These loggers distinguished the 4 main activities of black-legged kittiwakes during chick-rearing: attending the brood at the nest, travelling flight, active foraging flight and presence on the sea surface. The work was carried out on the Isle of May, southeast Scotland. Breeding success of black-legged kittiwakes at this colony has been very poor in recent years. Concern has been expressed that the presence of a large industrial sandeel fishery, operating about $40 \mathrm{~km}$ from the island in an area known to be used by black-legged kittiwakes for feeding (Wanless et al. 1998) has contributed to this poor performance (Rindorf et al. 2000, Lewis et al. 2001b). We fitted a series of models to time allocation of breeding adults during foraging trips. The models were designed to answer 2 specific questions that are key to understanding strategies in response to energetic constraints of rearing offspring and the variable availability of prey.

First, we examined the relationship between travelling flight duration and trip duration. Recent work on Northern gannets Morus bassanus in the North Sea has shown a very strong relationship between range and trip duration (Hamer et al. 2000, 2001). Hamer et al. suggest that distance travelled is not dictated by energetic constraints, but by the patchy distribution of prey; thus, gannets are travelling until they find food, and no upper limit in travelling time is detected. However, several other relationships between travelling time and trip duration are predicted under different energetic constraints and prey distribution patterns. For example, an upper limit to travelling time could occur if there is an energetic threshold associated with the costs of returning to the colony. Alternatively, travelling time could be driven by prey distribution, i.e. food is patchily distributed until a threshold distance from the colony beyond which profitability of food patches decreases to the extent that the cost of further travel outweighs the benefits.

Second, we investigated whether the ratio of time spent actively foraging vs time on the sea changed with increasing trip duration once travelling flight duration had been taken into account. Additional time spent on foraging would suggest increased profitabil- 
ity, a central prediction of foraging theory (Orians \& Pearson 1979). Alternatively, additional time spent inactive on the sea surface with increasing trip duration would suggest an energetic constraint associated with long trips. Finally, no change in ratio would suggest that time allocation is flexible, with foraging activity probably dictated in part by local foraging conditions.

\section{MATERIALS AND METHODS}

Data collection. The study was carried out at the black-legged kittiwake colony on the Isle of May National Nature Reserve, southeast Scotland (56 $11^{\circ}$ N, $\left.02^{\circ} 33^{\prime} \mathrm{W}\right)$, between 17 and 30 June 1999. Ten adult Rissa tridactyla were captured and equipped with activity loggers (dimensions: length $62 \mathrm{~mm}$, width 22 to $26 \mathrm{~mm}$, height 13 to $18.5 \mathrm{~mm}$; mass $18 \mathrm{~g}, 4$ to $6 \%$ body mass). All the birds sampled were in mid chick-rearing stage, with broods aged between 10 and $20 \mathrm{~d}$. The logger contained a motion sensor, which was a modified microphone with a membrane that was activated by body movements. During flight, the membrane was activated by the wing beats. The motion sensor had a recording interval of $6 \mathrm{~s}$. The logger also contained a saltwater switch (recording interval 4 s), consisting of 2 short electric wires (1 cm in length) emerging from the housing plug of the device. Short-circuiting of these wires occurred when the bird was fully submerged in water during foraging.

The devices were attached to feathers in the centre of the bird's back using Tesa tape ${ }^{\circledR}$ and cable ties. The attachment process took approx. $5 \mathrm{~min}$, and after release 9 birds returned to the nest site within $20 \mathrm{~min}$, with most returning within $2 \mathrm{~min}$ (comparable to return times after routine handling for ringing or taking morphometrics). The tenth bird immediately departed on a foraging trip because its mate had returned to the nest whilst the bird was being processed.

Potential impacts of the loggers on activity patterns and feeding trip durations were examined by observing the nest attendance of chick-rearing adults at a sample of nests in the same part of the colony as the instrumented birds. Two series of watches were carried out, each series spread across $6 \mathrm{~d}$. Daily observations were carried out for $3 \mathrm{~h}$ per day, timed to ensure that all hours from 04:00 to 22:00 were covered in each watch series (Watch 1: 62 nests, 6 d during the period 19 to 26 June; Watch 2: 51 nests:
6 d during the period 28 June to 5 July). During each observation period, we recorded the number of changeovers that occurred during each hour. Changeovers only took a few minutes to complete and chicks were never left unattended, so the average trip duration could be estimated from the changeover frequency (Hamer et al. 1993) and compared with that of the instrumented birds.

Of the 10 birds, 9 were recaptured 23 to $70 \mathrm{~h}$ after release, their activity loggers removed and the data downloaded to a laptop computer. Four different categories of signals from the flight sensors were identified that could be related to different activity patterns: (1) very weak, scarce, low-intensity signals that corresponded to periods when the bird was present on the nest; (2) weak, frequent signals of relatively low intensity that corresponded to periods when the bird was inactive on the sea surface; (3) strong signals with a characteristically stable intensity and frequency that corresponded to periods of steady, travelling flight; (4) strong signals showing extremely variable intensity and frequency that were assumed to correspond to foraging flight in which the bird alternated hovering, gliding and normal flight. Associated with this fourth type was the triggering of the saltwater switch, indicative of the bird submerging completely below the surface to feed. The saltwater switch is not triggered during any of the other activities because the device remains dry (Fig. 1).

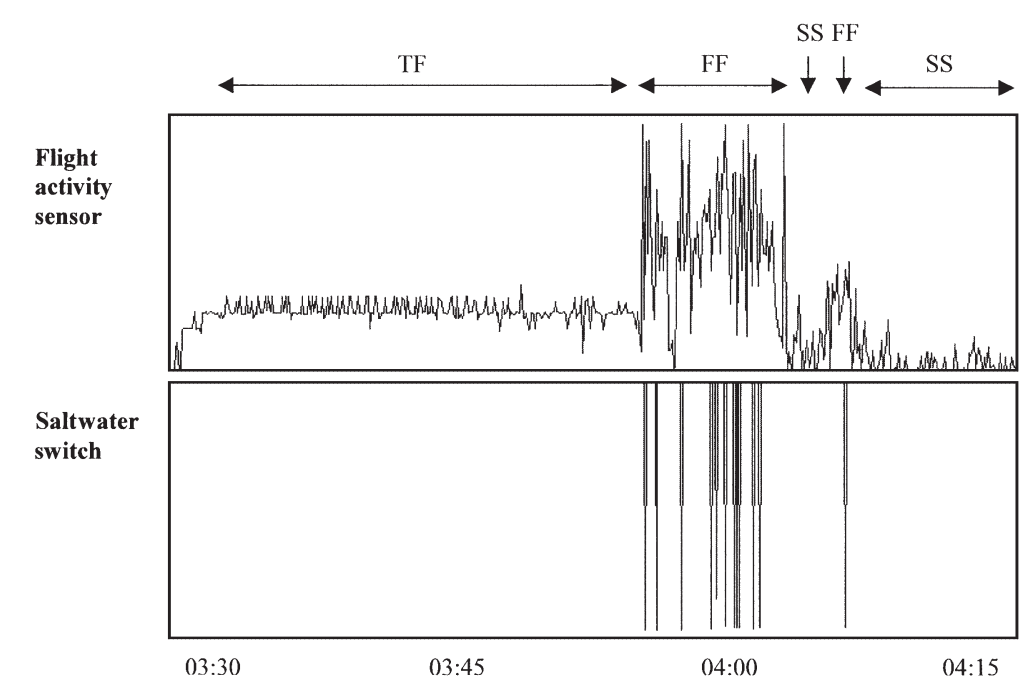

Fig. 1. Rissa tridactyla. Data collected by the flight activity sensor and saltwater switch from loggers attached to black-legged kittiwakes, showing the difference in signal obtained for the 3 activities recorded during a foraging trip from a bird at sea between 03:26 and 04:17 h on 22 June. Travelling flight (TF) consists of high, stable signals; foraging flight (FF) consists of strong signals of very variable intensity and frequency, together with activitation of the saltwater switch; presence on the sea surface (SS) consists of weak, frequent signals 
Frequent visual checks of nests of instrumented birds were made that enabled us to verify whether our interpretation of logger output was correct. In all cases, checks confirmed our assessment of when birds were away on trips or present in the colony.

Models. Four models were used to determine the relationship between travelling flight duration and trip duration: (M1) a fixed or constant model, whereby travelling flight duration is independent of trip duration, suggesting that prey are at a fixed distance from the colony, and additional time with increasing trip duration is spent foraging or inactive on the sea; (M2) a linear model, whereby travelling flight duration increases linearly with trip duration (Hamer et al. 2000); (M3) an asymptotic exponential model, whereby travelling flight duration initially increases with trip duration before the relationship levels off gradually, suggesting an energetic constraint on foraging costs associated with greater distance from the colony irrespective of the distribution of prey; (M4) a broken-stick model with a flat asymptote, whereby travelling flight duration initially increases linearly with trip duration, until a maximum travel time is attained beyond which additional time is spent on other activities. A maximum travelling time may occur if there is an energetic threshold set by the cost of returning to the colony, or could be dictated by the distribution of prey. The mathematical equations for these models were as follows:

$$
\begin{aligned}
& T F=c+\text { error } \\
& T F=c \cdot T+\text { error } \\
& T F=c \cdot\left(1-\mathrm{e}^{a \cdot T}\right)+\text { error } \\
& T F=c \cdot T+\text { error } \quad \text { if } T<b \\
& T F=c \cdot b+\text { error } \quad \text { if } T>b
\end{aligned}
$$

where $T F=$ travelling flight duration and $T=$ trip duration. To estimate the parameters $a, b, c$ as appropriate, the models were fitted by iteratively reweighted leastsquares, with weights of $1 / T^{2}$ suggested by residual plots. Thus, variance was proportional to the square of trip length, rather than the square of fitted values, to ensure that all models were comparable. For each model we saved the residual sums of squares, the percentage of the variance explained, and the best fitting parameter estimates.

Table 1. Rissa tridactyla. Deployment and recapture dates (1999), length of deployment, number of trips undertaken during the de-

\begin{tabular}{|c|c|c|c|c|c|c|c|}
\hline Bird & $\begin{array}{c}\text { Deployment } \\
\text { date }\end{array}$ & $\begin{array}{l}\text { Recapture } \\
\text { date }\end{array}$ & $\begin{array}{c}\text { Length of } \\
\text { deployment }(\mathrm{h})\end{array}$ & Trips & $\mathrm{d} / \mathrm{n}$ & $\begin{array}{l}\text { Trip duration } \\
\text { (h) }\end{array}$ & $\begin{array}{c}\text { Nest } \\
\text { duration (h) }\end{array}$ \\
\hline 1 & 17 June & 20 June & 70.6 & 7 & $\begin{array}{l}\mathrm{d} \\
\mathrm{n} \\
\mathrm{d} \\
\mathrm{n} \\
\mathrm{d} \\
\mathrm{n} \\
\mathrm{d}\end{array}$ & $\begin{array}{l}3.5 \\
7.5 \\
2.3 \\
4.0 \\
7.3 \\
9.4 \\
7.2\end{array}$ & $\begin{array}{c}9.0 \\
2.6 \\
2.9 \\
4.5 \\
3.4 \\
4.8 \\
-\end{array}$ \\
\hline 2 & 20 June & 22 June & 48.5 & 4 & $\begin{array}{l}\mathrm{d} \\
\mathrm{d} \\
\mathrm{d} \\
\mathrm{d}\end{array}$ & $\begin{array}{l}5.5 \\
5.9 \\
4.7 \\
5.1\end{array}$ & $\begin{array}{c}8.6 \\
4.5 \\
5.6 \\
-\end{array}$ \\
\hline 3 & 22 June & 23 June & 25.3 & 2 & $\begin{array}{l}\mathrm{d} \\
\mathrm{d}\end{array}$ & $\begin{array}{l}6.0 \\
4.5\end{array}$ & $\begin{array}{c}9.7 \\
-\end{array}$ \\
\hline 4 & 23 June & 24 June & 23.3 & 1 & d & 5.3 & - \\
\hline 5 & 24 June & 25 June & 23.1 & 2 & $\begin{array}{l}\mathrm{d} \\
\mathrm{d}\end{array}$ & $\begin{array}{l}2.1 \\
6.4\end{array}$ & $\begin{array}{c}6.7 \\
-\end{array}$ \\
\hline 6 & 25 June & 27 June & 34.7 & 2 & $\begin{array}{l}\mathrm{d} \\
\mathrm{n}\end{array}$ & $\begin{array}{l}9.1 \\
9.7\end{array}$ & $\begin{array}{c}8.3 \\
-\end{array}$ \\
\hline 7 & 27 June & 28 June & 24.5 & 2 & $\begin{array}{l}\mathrm{d} \\
\mathrm{d}\end{array}$ & $\begin{array}{l}9.2 \\
3.6\end{array}$ & $\begin{array}{c}10.2 \\
-\end{array}$ \\
\hline 8 & 28 June & 29 June & 23.5 & 2 & $\begin{array}{l}\mathrm{d} \\
\mathrm{d}\end{array}$ & $\begin{array}{l}7.6 \\
3.5\end{array}$ & $\begin{array}{c}5.9 \\
-\end{array}$ \\
\hline 9 & 29 June & 30 June & 28.9 & 2 & $\begin{array}{l}\mathrm{d} \\
\mathrm{d}\end{array}$ & $\begin{array}{l}1.7 \\
9.9\end{array}$ & $\begin{array}{c}15.2 \\
-\end{array}$ \\
\hline
\end{tabular}
ployment period, diurnal period of trip $(\mathrm{d}=$ daytime; $\mathrm{n}=$ nighttime, i.e. including midnight), trip duration and length of time spent on the nest after each trip (nest duration) for the 9 birds studied. Allocation of time to nest attendance vs foraging was calculated by taking the mean trip duration to nest duration proportion per bird, and then averaging across birds. On average, birds spent $41.2 \%$ of time foraging and $58.8 \%$ attending the brood. -: For each bird, final nest duration interrupted by recapture so data exluded 
We subsequently analysed whether there was any pattern of time allocated to foraging flight and time on the sea surface with respect to trip duration, once travelling flight had been taken into account. We fitted models to $p_{T F}, p_{F F}$ and $p_{S S}$ the proportions of time spent on travelling flight $(T F)$, foraging flight $(F F)$ and on the sea surface $(S S)$ respectively, with the following mathematical equations:

$$
\begin{aligned}
& p_{T F}=c \\
& p_{F F}=d_{0} \cdot\left(1-p_{T F}\right) \\
& p_{S S}=\left(1-d_{0}\right) \cdot\left(1-p_{T F}\right) \\
& p_{T F}=c \text { if } T<b_{i} \quad p_{T F}=c \cdot b / T \text { if } T>b \\
& p_{F F}=d_{0} \cdot\left(1-p_{T F}\right) \\
& p_{S S}=\left(1-d_{0}\right) \cdot\left(1-p_{T F}\right) \\
& p_{T F}=c \text { if } T<b_{i} \quad p_{T F}=c \cdot b / T \text { if } T>b \\
& p_{F F}=d_{T} \cdot\left(1-p_{T F}\right) \\
& p_{S S}=\left(1-d_{T}\right) \cdot\left(1-p_{T F}\right)
\end{aligned}
$$$$
\text { where } d_{T}=d_{0}+d_{1} \cdot(T-T) \text { and } T=327.6 \text { is the mean }
$$$$
\text { trip duration. }
$$

Thus, in Model M5 the parameters $c$ and $d_{0}$ define a constant partitioning of trip duration into the 3 activities; Model M6 elaborates on M5 by placing an upper limit, $c \cdot b$, on travelling flight duration as suggested by the fit of Model M4; Model M7 has the additional extension of the parameter $d_{1}$ determining a partitioning of non-travel-flight duration between foraging flight and sea surface dependent on trip duration.

To estimate the model parameters, $b, c, d 0, d_{1}$, as appropriate, the models were fitted by iteratively reweighted least-squares. The objective function was the sum of the squared differences between observed and fitted proportions. To balance the influence of data points regardless of where their fitted values lay between 0 and 1 , the inverse of the square of the product of fitted proportion and (1 - fitted proportion) was used as weights.

\section{RESULTS}

\section{Time allocation}

A total of $302 \mathrm{~h}$ of activity was recorded from the 9 birds, including 24 complete feeding trips (Table 1). On average, instrumented birds spent $59 \%$ of time at the nest and $41 \%$ on feeding trips (Table 1). Feeding trips ranged in duration from 1.7 to $9.9 \mathrm{~h}$, with a mean of $5.9 \pm 2.5 \mathrm{SD} h(\mathrm{n}=24)$. Trip durations of uninstrumented birds were comparable $(7.8 \mathrm{~h}, \mathrm{n}=113)$.

There was no evidence of a pattern in the timing of foraging trips, with birds leaving the colony throughout the day (Fig. 2; frequency of changeover 06:00 to

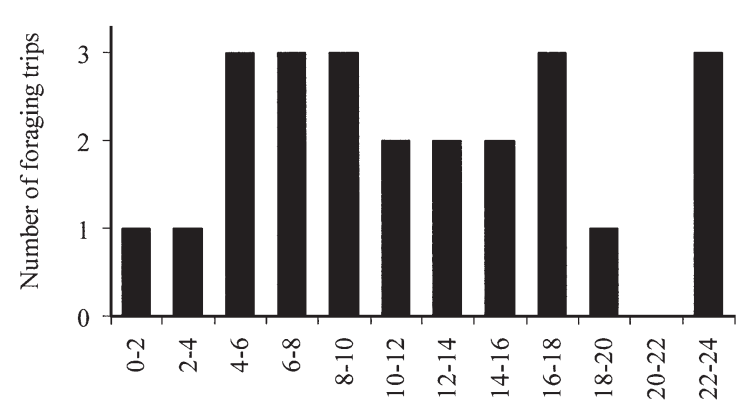

Hour of day

Fig. 2. Rissa tridactyla. Departure times of instrumented black-legged kittiwakes during the chick-rearing period ( $\mathrm{n}=$ 24 trips)

18:00 h vs $18: 00$ to $06: 00 \mathrm{~h}: \chi^{2}=0.34$, not significant). However, there was a strong diurnal pattern to time allocation at sea, with flight activity highest in the morning and late evening but no records during the middle of the night. Thus, no foraging flight occurred between 23:00 and 02:00 h GMT and no travelling flight was recorded between 00:00 and 01:00 h GMT (Fig. 3). Overall time allocation for the 24 trips is given in Table 2.

Four trips were excluded from the models of time allocation, since birds were absent overnight. These trips were characterised by significantly longer periods on the sea surface than daytime trips (\% of trip spent on the sea surface; overnight: $52.1 \%$; daytime $25.0 \%$, angular-transformed: $t_{22}=3.80, \mathrm{p}<0.001$ ) because of the absence of active foraging during the darkest

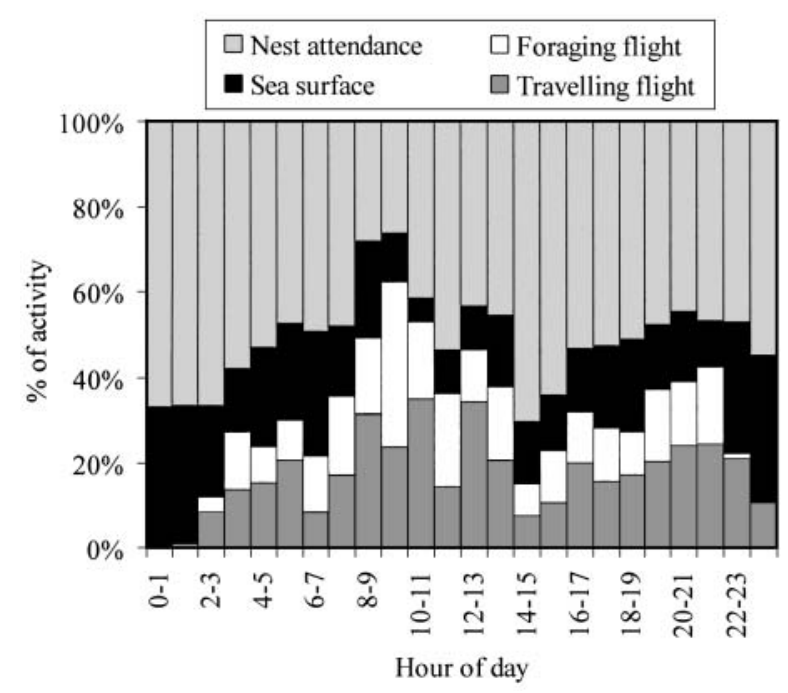

Fig. 3. Rissa tridactyla. Daily activity patterns in terms of travelling flight, foraging flight, presence on the sea surface and nest attendance during the chick-rearing period. Percentages represent the means for 9 birds 
Table 2. Rissa tridactyla. Time allocated to travelling flight (TF), foraging flight (FF) and presence on the sea surface (SS) during foraging trips. Means per bird are shown where more than one trip was recorded (see Table 1)

\begin{tabular}{|lccc|}
\hline Bird & TF & FF & SS \\
\hline 1 & 0.32 & 0.40 & 0.28 \\
2 & 0.48 & 0.26 & 0.26 \\
3 & 0.58 & 0.24 & 0.17 \\
4 & 0.40 & 0.16 & 0.44 \\
5 & 0.43 & 0.22 & 0.35 \\
6 & 0.23 & 0.28 & 0.49 \\
7 & 0.46 & 0.22 & 0.32 \\
8 & 0.43 & 0.27 & 0.30 \\
9 & 0.46 & 0.36 & 0.18 \\
Mean & 0.42 & 0.27 & 0.31 \\
SD & 0.10 & 0.07 & 0.11 \\
Mean total time & 0.17 & 0.11 & 0.13 \\
\hline
\end{tabular}

Table 3. Rissa tridactyla. Results of 4 models of relationship between travelling flight duration and trip duration (Fig. 1). M4 (broken-stick model) provided the best fit to the data, explaining $74.7 \%$ of the variance. M1, 2, 3 were fixed, linear and asymptotic exponential models respectively (see 'Materials and methods')

\begin{tabular}{|lccc|}
\hline Model & $\begin{array}{c}\text { Residual } \\
\text { df }\end{array}$ & $\begin{array}{c}\text { Residual sum } \\
\text { of squares }\end{array}$ & $\begin{array}{c}\text { Residual mean } \\
\text { square }\end{array}$ \\
\hline M1 & 19 & 8050 & 423.7 \\
M2 & 19 & 2716 & 142.9 \\
M3 & 18 & 2004 & 111.3 \\
M4 & 18 & 1951 & 108.4 \\
\hline
\end{tabular}

periods of the night (Fig. 3). In addition, overnight trips tended to be longer (trip duration: overnight $476.3 \pm$ 35.9 SE min, daytime $327.6 \pm 33.6 \mathrm{SE} \mathrm{min,} t_{22}=1.91$, $\mathrm{p}=0.069)$.

\section{Model outputs}

The results of the 4 candidate models used to describe the relationship between travelling flight and trip duration for the 20 daytime trips are shown in Table 3. The best fit to the data was provided by the broken-stick model with flat asymptote (M4), which explained $74.7 \%$ of the variance (Fig. 4). The travelling flight asymptote was estimated as $186 \pm 24 \mathrm{~min}$, with the break point occurring at a trip duration of $386 \pm$ 56 min. Thus, for trips greater than ca. $6.5 \mathrm{~h}$, there was no increase in travelling flight duration with increasing trip duration. Using published estimates for average flight speed of black-legged kittiwakes (13.1 $\mathrm{m} \mathrm{s}^{-1}$ : Pennycuick 1997), we estimated maximum range from the following equation:

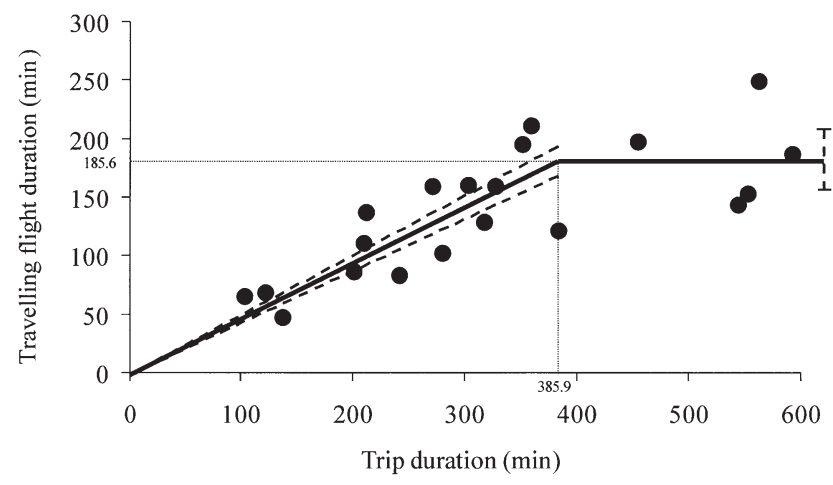

Fig. 4. Rissa tridactyla. Relationship between travelling flight duration and trip duration for the 20 daytime foraging trips recorded, showing the model with the best fit, the broken stick model with a flat asymptote model (M4: see Table 3). Parameter $c$ was estimated as $0.48 \pm 0.028$ (standard errors for $\mathrm{y}$-asymptote and $c$ conditional on the position of the break point). The estimates for the travelling flight duration asymptote and the trip duration at the position of the break point are given alongside the $\mathrm{y}$ - and $\mathrm{x}$-axes respectively

$$
\frac{\text { Max. range }(\mathrm{km})=(186 \pm 42 \mathrm{~min}) \cdot 13 \mathrm{~m} \mathrm{~s}^{-1}}{2}
$$

Thus, the black-legged kittiwakes in this study were foraging within a maximum range of $73 \pm 9 \mathrm{~km}$.

Sequential fitting of Models M5, M6 and M7 found no evidence for a change in the ratio of foraging flight to sea surface time as trip duration increased, once travelling flight had been taken into account (Table 4).

\section{DISCUSSION}

The breeding success of black-legged kittiwakes on the Isle of May in 1999 was low (0.20 chicks fledged per pair), maintaining the run of poor breeding seasons during the 1990s (decadal average 0.29 chicks fledged per pair, $\mathrm{n}=10 \mathrm{yr}$ : Bull et al. 2000). During this period,

Table 4. Rissa tridactyla. Cumulative analysis of variance for sequence of 3 models to determine whether the ratio of foraging flight to presence on the sea surface varies with trip duration. In M5 there is a constant partitioning between the 3 activities (travelling flight, foraging flight, sea surface). M6 and M7 place an upper limit on travelling flight as suggested by broken-fit model M4, independent of and dependent on trip duration respectively

\begin{tabular}{|lccccc|}
\hline Model & df & $\begin{array}{c}\text { Residual } \\
\text { df }\end{array}$ & $\begin{array}{c}\text { Residual } \\
\text { sum of } \\
\text { squares }\end{array}$ & $\begin{array}{c}\text { Change in } \\
\text { sum of } \\
\text { squares }\end{array}$ & $F$ \\
\hline M5 & 2 & 38 & 19.10 & & \\
M6 & 3 & 37 & 16.99 & 2.11 & 4.54 \\
M7 & 4 & 36 & 16.73 & 0.26 & 0.55 \\
\hline
\end{tabular}


survival of breeding adults also declined significantly and the number of pairs decreased by $50 \%$ (Hemsley 1999, Harris et al. 2000). Thus there is an urgent need to improve our understanding of the feeding ecology and behaviour of this species, which is widely used as an indicator of marine conditions in the North Atlantic and North Pacific. In recent years, the application of locational transmitters and activity loggers has greatly improved our understanding of the foraging ecology of numerous seabird species (e.g. Jouventin \& Weimerskirch 1990, Benvenuti et al. 1998). Our deployment of novel activity loggers provides the most detailed description of at-sea behaviour yet available for the black-legged kittiwake and has revealed some important spatial and temporal patterns. Weight of the loggers used was 4 to $6 \%$ of the mass of the birds. Although this is near the limit generally regarded as acceptable for a flying bird, kittwakes have a relatively low wing loading that should mitigate the impact of the devices (Pennycuick 1997, Kenward 2000). We could detect no differences in the behaviour of deviced and control birds, so have no reason to believe that the birds were not foraging normally.

The birds divided their time approximately equally between being at the colony and away feeding. Arrivals at and departures from the colony did not show any clear diurnal pattern, but while away, birds spent less time in flight between sunset and sunrise. Birds did not fly at all during the darkest part of the night, consistent with the view that black-legged kittiwakes are visual feeders (Cramp \& Simmons 1983).

The relationship between the length of time spent travelling and the total length of a daytime trip was best described by a broken-stick model with a flat asymptote. Initially, travel time increased linearly with trip duration, accounting for approximately half of the time away from the colony, but for trips lasting longer than $6.5 \mathrm{~h}$ there was no further increase in travel time. Combining our data with those on the average flight speed of the black-legged kittiwake (Pennycuick 1997) suggested a maximum foraging range of $73 \pm 9 \mathrm{~km}$. This estimate is slightly greater than that recorded for black-legged kittiwakes in Alaska (maximum range at Shoup Bay, a colony of similar size to the Isle of May = 40 to $60 \mathrm{~km}$, data from $4 \mathrm{yr}_{\text {; }}$ Suryan et al. 2000). Our estimate assumes that birds followed either a linear or narrow elliptical flight path when travelling to and from the feeding area. These assumptions are supported by our own visual observations at the colony and radio-tracking studies of birds away at sea (Wanless et al. 1992, E. M. Humphreys pers. comm.). Our method of estimating range will hopefully be further improved by using real-flight speeds for individuals and incorporating the effects of weather conditions, particularly wind speed and direction. Such refine- ment should be achievable with the next generation of activity loggers, which will hopefully also provide locational data.

Our findings are in contrast to another recently studied North Sea species, the Northern gannet, which shows a linear relationship between foraging range and trip duration and no maximum range detected (Hamer et al. 2000, 2001). A maximum foraging range for a bird tied to a colony by the need to feed its chick may come about by intrinsic energetic constraints and/or extrinsic factors (Orians \& Pearson 1979, Obst et al. 1995, Lewis et al. 2001a). We did not measure flight costs, but the species' low wing loading makes the former perhaps unlikely. During the period that the loggers were deployed in 1999, and in every year since we started collecting data in 1985, the bulk of the food brought to young black-legged kittiwakes at this colony was lesser sandeels (Harris \& Wanless 1997, Lewis et al. 2001b). One of the main marine features within $73 \mathrm{~km}$ of the Isle of May is an area of shallow, productive fishing ground known as Wee Bankie and Marr Bank (Fig. 5). This area has large numbers of lesser sandeels, and a commercial fishery has been operating in the area since 1990, with peak landings of over 100000 t in 1993 (ICES 1994; Wright \& Begg 1997). At sea surveys of marine birds have recorded large numbers of black-legged kittiwakes feeding there, and radio-tracking studies in 1999 found that most adult black-legged kittiwakes from the Isle of May were flying to feeding grounds between $45^{\circ}$ and $135^{\circ} \mathrm{N}$ of the island (Wanless et al. 1998, Camphuysen \& Webb 1999, E. M. Humphreys pers. comm.). The most parsimonious explanation of the available data is that black-legged kittiwakes breeding on the Isle of May feed in this area.

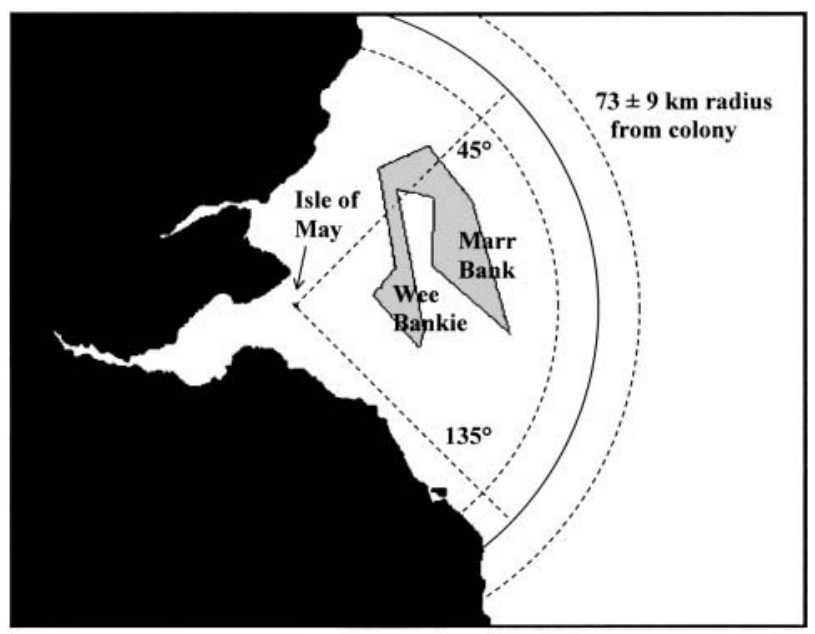

Fig 5. Rissa tridactyla. Map showing studied colony of Rissa tridactyla, Wee Bankie and Marr Bank, maximum foraging range of $73 \pm 9 \mathrm{~km}$, and 45 and $135^{\circ}$ radii 
We found no consistent pattern in the ratio between foraging flight and sea surface time with increasing trip duration. Thus, the extra time generated by the limit placed on travelling flight appeared to be distributed randomly between the 2 main alternative behaviours, suggesting that foraging strategies in the blacklegged kittiwake are likely to be flexible, probably governed by the feeding conditions that the bird is facing at the time.

The numbers of black-legged kittiwakes on the Isle of May have declined consistently throughout the 1990s. There is a close link between breeding success and availability of lesser sandeels at this and other colonies (Wright 1996, Rindorf et al. 2000, Lewis et al. $2001 \mathrm{~b})$. The black-legged kittiwake is particularly vulnerable to the effects of food shortage because it is a surface feeder, and therefore unable to exploit prey more than a few centimetres below the surface (Furness \& Tasker 2000). Our results from the Isle of May indicate that breeding adults forage in areas where prey abundance is high within a maximum range, and adopt flexible foraging strategies in response to local conditions. Foraging areas overlap with a large sandeel fishery (ICES 2001). The extent to which black-legged kittiwakes and the fishery interact, and in particular whether there is competition between them, remains uncertain (Lewis et al. 2001b). The temporary closure of the fishery since 2000 provided us with the opportunity to assess foraging time allocation within and among seasons in the absence of a fishery. By building an understanding of the underlying environmental parameters dictating black-legged kittiwake activity budgets, we will be in a stronger position to judge the impact the fishery has on foraging behaviour.

Acknowledgements. We thank Scottish Natural Heritage for permission to work on the Isle of May National Nature Reserve. The instruments and the computer software were developed by Alberto Ribolini, to whom we express our gratitude. The study was supported by grants from the University of Pisa and the Ministero dell'Universita e della Ricerca Scientifica e Tecnologica (MURST). We thank Sue Lewis and the anonymous referees for comments on the manuscript, and Liz Humphreys for information.

\section{LITERATURE CITED}

Aebischer NJ, Coulson JC, Colebrook JM (1990) Parallel long-term trends across four marine trophic levels and weather. Nature 347:753-755

Benvenuti S, Bonadonna F, Dall'Antonia L, Gudmundsson GA (1998) Foraging flights of breeding thick-billed murres in Iceland as revealed by bird-borne direction recorders. Auk 115:57-66

Benvenuti S, Dall'Antonia L, Lyngs P (2001) Foraging behaviour and time allocation of chick-rearing razorbills Alca torda at Græsholmen, central Baltic Sea. Ibis 143:402-412

Benvenuti S, Dall'Antonia L, Falk K (2002) Diving behaviour differs between incubating and brooding Brunnich's guillemots, Uria lomvia. Polar Biol 25:474-478

Bull J, Wanless S, Harris MP (2000) Isle of May seabird studies in 1999. In: Joint Nature Conserve Committee Report No. 303. JNCC, Aberdeen

Bonadona F, Holland R, Dall'Antonia L, Guilford T, Benvenuti S (2000) Tracking clock-shifted homing pigeons from familiar release sites. J Exp Biol 203:207-212

Camphuysen CJ, Webb A (1999) Multi-species feeding associations in North Sea seabirds: jointly exploiting a patchy environment. Ardea 87:177-198

Cramp S, Simmons KEL (1983) Handbook of the birds of Europe, the Middle East and North Africa. The birds of the Western Palearctic, Vol. III. Oxford University Press, Oxford

Dall'Antonia P, Dall'Antonia L, Ribolini A (1993) Flight path reconstruction of birds by a route recorder. In: Mancini P et al. (eds) Biotelemetry XII. Proc 12th Int Symp Biotelem, Litografia Felici, Pisa, p 544-549

Dall'Antonia L, Dall'Antonia $\mathrm{P}$, Benvenuti $\mathrm{S}$, Ioalè $\mathrm{P}$, Massa B, Bonnadonna F (1995) The homing behaviour of Cory's shearwater (Calonectris diomedia) studied by means of a direction recorder. J Exp Biol 198:359-362

Dall'Antonia L, Gudmundsson GA, Benvenuti S (2001) Time allocation and foraging pattern of chick-rearing Razorbills in northwest Iceland. Condor 103:469-480

Falk K, Benvenuti S, Dall'Antonia L, Kampp K, Ribolini A (2000) Time allocation and foraging behaviour of chickrearing Brünnich's guillemots Uria lomvia in high-arctic Greenland. Ibis 142:82-92

Falk K, Benvenuti S, Dall'Antonia L, Gilchrist G, Kampp K (2002) Foraging behaviour of thick-billed murres breeding in different sectors of the North Water polynya: an intercolony comparison. Mar Ecol Prog Ser 231:293-302

Furness RW, Tasker ML (2000) Seabird-fishery interactions: quantifying the sensitivity of seabirds to reductions in sandeel abundance, and identification of key areas for sensitive seabirds in the North Sea. Mar Ecol Prog Ser 202: $354-364$

Garthe S, Benvenuti S, Montevecchi WA (2000) Pursuit plunging by Northern gannets (Sula bassana) feeding on capelin (Mallotus villosus). Proc R Soc Lond Ser B Biol Sci 267:1717-1722

Gill VA, Hatch SA (2002) Components of productivity in black-legged kittiwakes Rissa tridactyla: response to supplemental feeding. J Avian Biol 33:113-126

Gill VA, Hatch SA, Lanctot RB (2002) Sensitivity of breeding parameters to food supply in black-legged kittiwakes Rissa tridactyla. Ibis 144:268-283

Gislason H, Kirkegaard E (1998) Is the industrial fishery in the North Sea sustainable? In: Symes D (ed) Northern waters: management issues and practice. Fishing News Books, Blackwell, Oxford, p 195-207

Golet GH, Irons DB, Costa DP (2000) Energy costs of chick rearing in black-legged kittiwakes (Rissa tridactyla). Can J Zool 78:982-991

Hamer KH, Monaghan P, Uttley JD, Walton P, Burns MD (1993) The influence of food supply on the breeding ecology of Kittiwakes Rissa tridactyla in Shetland. Ibis 135: 255-263

Hamer KC, Phillips RA, Wanless S, Harris MP, Wood AG (2000) Foraging ranges, diets and feeding locations of gannets Morus bassanus in the North Sea: evidence from satellite telemetry. Mar Ecol Prog Ser 200:257-264

Hamer KC, Phillips RA, Hill JK, Wanless S, Wood AG (2001) Contrasting foraging strategies of gannets Morus bassanus at two North Atlantic colonies: prey patchiness and foraging area fidelity. Mar Ecol Prog Ser 224:283-290 
Harris MP, Wanless S (1997) Breeding success, diet, and brood neglect in the kittiwake (Rissa tridactyla) over an 11-year period. ICES J Mar Sci 54:615-623

Harris MP, Wanless S, Rothery P (2000) Adult survival rates of shag Phalacrocorax aristotelis, common guillemot Uria aalge, razorbill Alca torda, puffing Fratercula arctica and kittiwake Rissa tridactyla on the Isle of May 1986-1996. Atl Seabirds 2:133-150

Harrison P (1983) Seabirds: an identification guide. Christopher Helm, London

Hemsley D (1999) Studies of breeding birds and other biological recording on the Isle of May in 1999. Scott Nat Heritage Rep. SNH, Edinburgh

Kenward RE (2000) A manual for wildlife radio tagging. Academic Press, London

ICES (International Council for the Exploration of the Sea) (1994) Reports of the ICES Advisory Committee on Fishery Management 1993. Parts 1 and 2. Int Counc Explor Sea Coop Res Rep 196

ICES (International Council for the Exploration of the Sea) (2001) Report of the ICES Advisory Committee on Fishery Management 2000. Int Counc Explor Sea Coop Res Rep 242

Jouventin P, Weimerskirch H (1990) Satellite tracking of wandering albatrosses. Nature 343:476-478

Lewis S, Sherratt TN, Hamer KC, Wanless S (2001a) Evidence of intraspecific competition for food in a pelagic seabird. Nature 412:816-819

Lewis S, Wanless S, Wright PJ, Harris MP, Bull J, Elston DA (2001b) Diet and breeding performance of black-legged kittiwakes Rissa tridactyla at a North Sea colony. Mar Ecol Prog Ser 221:277-284

Lewis S, Benvenuti S, Dall'Antonia L, Griffiths R, Money L, Sherratt TN, Wanless S, Hamer KC (2002) Sex specific foraging behaviour of a monomorphic seabird. Proc R Soc Lond Ser B Biol Sci 269:1687-1693

Lloyd C, Tasker ML, Partridge K (1991) The status of seabirds in Britain and Ireland. Poyser, London

Obst BS, Russell RW, Hunt GL Jr, Eppley ZA, Harrison NM (1995) Foraging radii and energetics of least auklets (Aethia pusilla) breeding on three Bering Sea islands. Physiol Zool 68:647-672

Orians GH, Pearson NE (1979) On the theory of central place

Editorial responsibility: Otto Kinne (Editor),

Oldendorf/Luhe, Germany foraging. In: Horn DJ, Stairs GR, Mitchell RD (eds) Analysis of ecological systems. Ohio State University Press, Columbus, p 155-177

Papi F, Ioalè P, Dall'Antonia L, Benvenuti S (1991) Homing strategies of pigeons investigated by clock shift and flight path reconstruction. Naturwissenschaften 78:370-373

Pennycuick CJ (1997) Actual and 'optimum' flight speeds: field data reassessed. J Exp Biol 200:2355-2361

Rindorf A, Wanless S, Harris MP (2000) Effects of changes in sandeel availability on the reproductive output of seabirds. Mar Ecol Prog Ser 202:241-252

Suryan RM, Irons DB, Benson J (2000) Prey switching and variable foraging strategies of black-legged kittiwakes and the effect on reproductive success. Condor 102: $374-384$

Suryan RM, Irons DB, Kaufman M, Benson J, Jodice PGR, Roby DD, Brown ED (2002) Short-term fluctuations in forage fish availability and the effect on prey selection and brood-rearing in the black-legged kittiwake Rissa tridactyla. Mar Ecol Prog Ser 236:273-287

Upton AJ, Pickerell G, Heubeck M (2000) Seabird numbers and breeding success in Britain and Ireland, 1999. Joint Nature Conservation Committee, UK Nature Conservation No. 24, Joint Nature Conservation Committee, Peterborough

Wanless S, Harris MP (1992) Activity budgets, diet and breeding success of kittiwakes Rissa tridactyla on the Isle of May. Bird Study 39:145-154

Wanless S, Monaghan P, Uttley JD, Walton P, Morris JA (1992) A radio-tracking study of kittiwakes (Rissa tridactyla) foraging under suboptimal conditions. In: Priede IG, Swift SM (eds) Wildlife telemetry. Remote monitoring and tracking of animals. Ellis Horwood, New York, p 580-590

Wanless S, Harris MP, Greenstreet SPR (1998) Summer sandeel consumption by seabirds breeding in the Firth of Forth, south-east Scotland. ICES J Mar Sci 55:1141-1151

Wright PJ (1996) Is there conflict between sandeel fisheries and seabirds? A case study at Shetland. In: Greenstreet SPR, Tasker ML (eds) Aquatic predators and their prey. Fishing News Books, Oxford, p 154-165

Wright PJ, Begg GS (1997) A spatial comparison of common guillemots and sandeels in Scottish waters. ICES J Mar Sci 54:578-592

Submitted: February 22, 2002; Accepted: September 17, 2002 Proofs received from author(s): December 2, 2002 